AL-IQTISHOD: Jurnal Pemikiran dan Penelitian Ekonomi Islam

E-ISSN: 2745-85I2 P-ISSN: 2407-6600

Volume 9 Issue I Januari 202I | Page: 093-103

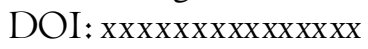

\title{
Implementasi Marketing Mix \\ Dalam Pemasaran Perbankan Syariah
}

\section{Eko Mardiyanto}

STAI Al-Azhar Menganti Gresik

Ekomardiyanto75@gmail.com

Abstract: Bank marketing is a process for creating and exchanging bank products or services aimed at meeting customer needs and desires by providing satisfaction. Marketing mix is an integrated marketing activity. each element cannot run independently without the support of other elements. The elements in the marketing mix are product, price, place and promotion. The implementation of the marketing mix greatly affects the marketing level of Islamic banking. The marketing mix strategy of Islamic banking includes product policies, prices, promotions, distribution places and channels, employee services, service processes, and the physical form of the Sharia Bank office itself.

Keywords: Marketing Mix, price, product promotion, place

Abstrak: Pemasaran bank adalah suatu proses untuk menciptakan dan mempertukarkan produk atau jasa bank yang ditujukan untuk memenuhi kebutuhan dan keinginan nasabah dengan cara memberikan kepuasan. Marketing mix merupakan kegiatan pemasaran yang dilakukan secara terpadu. setiap elemen tidak dapat berjalan sendiri-sendiri tanpa dukungan dari elemen lain. Elemen-elemen yang ada dalam marketing mix adalah produk (product), Harga (Price), Lokasi ( Place) dan promosi (promotion). Implementasi marketing mix sangat mempengaruhi tingkat pemasaran perbankan syariah. Strategi bauran pemasaran (marketing mix) perbankan suariah di dalamnya meliputi kebijakan produk, harga, promosi, tempat dan saluran distribusi, pelayanan pegawai, proses pelayanan, dan bentuk fisik kantor Bank Syariah itu sendiri.

Kata Kunci: Marketing Mix, harga, produk promotion, place 



\section{A. Pendahuluan}

Syariah marketing adalah sebuah disiplin bisnis strategis yang mengarahkan proses pencitraan, penawaran, dan perubahan value dari suatu inisiator kepada stakeholders-nya, yang dalam seluruh prosesnya sesuai dengan akad dan prinsipprinsip muamalah dalam Islam. Sepanjang hal tersebut dapat dijamin dan penyimpangan prinsip-prinsip muamalah islami tidak terjadi dalam suatu transaksi atau dalam prosses suatu bisnis, maka bentuk transaksi apapun dalam pemasaran dibolehkan.

Ada 4 karakteristik syariah marketing yang dapat menjadi panduan bagi para pemasar sebagai berikut: ${ }^{1}$

I. Teistis (Rabbaniyyah) yakni salah satu ciri khas syariah marketing yang tidak dimiliki dalam pemasaran konvensional yang dikenal selama ini adalah sifatnya yang religius. Jiwa seorang syariah marketer meyakini bahwa hukum-hukum syariat yang teistis atau yang bersifat ketuhanan ini adalah hukum yang paling adil, paling sempurna, paling selaras dengan segala bentuk kebaikan, paling dapat mencegah segala bentuk kerusakan, paling mampu mewujudkan kebenaran, memusnahkan kebatilan dan menyebarluaskan kemaslahatan.

2. Etis (Akhlaqiyyah) Keistimewaan yang lain dari seorang syariah marketer selain karena teistis, juga karena ia sangat mengedepankan masalah akhlaq (moral dan etika) dalm seluruh aspek kegiatannya. Dengan demikian, syariah marketing adalah konsep pemasar5an yang sangat mengedepankan nilai-nilai moral dan etika, tidak peduli apapun agamanya. Karena nilai moral dan etika adalah nnilai yang bersifat universal yang diajarkan oleh semua agama.

3. Realistis ( Al- Waqïiyyah) Syariah marketing adalah konsep pemasaran yang fleksibel, sebagaimana keluasaan dan keluwesan syariah Islamiyah yang

\footnotetext{
${ }^{1}$ Kambali, M. (2020). Analisa Faktor-Faktor Yang Mempengaruhi Keputusan Nasabah Untuk Menggunakan Jasa Bank Syariah Mandiri (Studi Kasus Pada Nasabah Bank Syari'ah Mandiri Gresik). AL IQTISHOD: Jurnal Pemikiran Dan Penelitian Ekonomi Islam, 8(1), 53-61. Retrieved from https://jurnal.stai-alazharmenganti.ac.id/index.php/Allqtishod/article/view/88
}

Volume. 9/No. I/Januari 202I A1-Iqtishod|93 
Implementasi Marketing Mix ....

melandasinya. Ia sangat memahami bahwa dalam situasi pergaulan di lingkungan yang sangat heterogen, dengan beragam suku, agama, dan ras, ada ajaran yang diberikan oleh Allah S.W.T dan dicontohkan oleh Nabi untuk bersikap lebih bersahabat, santun dan simpatik terhadap saudara-saudaranya dari umat lain.

4. Humanistis ( Al- Insaniyyah) Pengertian Humanistis adalah bahwa syariah diciptakan untuk manusia agar derajatnya terangkat, sifat kemanusiaannya terjaga dan terpelihara serta sifat-sifat kehewanannya dapat terkekang dengan panduan syariah. Dengan memiliki nilai Humanistis, ia menjadi manusia yang terkontrol dan seimbang, bukan manusia yang serakah, yang menghalalkan segala cara untuk meraih keuntungan yang sebesar-besarnya, bukan menjadi manusia yang bahagia di atas penderitaan orang lain, atau manusia yang hatinya kering dengan kepedulian sosial.

Oleh karena itu, penelitian ini bermaksud mengkaji bagaimana implementasi marketing mix dalam pemasaran bank syariah yang ada di indonesia dewasa ini. Dengan demikian diharapkan melalui penelitian ini didapat kondisi obyektif tentang pemasaran bank syariah dewasa ini.

\section{B. Kajian Pustaka}

\section{Marketing Mix (Bauran Pemasaran)}

Marketing mix ( bauran pemasaran) adalah kumpulan alat pemasaran taktis terkendali yang dipadukan perusahaan untuk menghasilkan respon yang diinginkannya di pasar sasaran. ${ }^{2}$ Marketing mix merupakan kegiatan pemasaran yang dilakukan secara terpadu . setiap elemen tidak dapat berjalan sendiri-sendiri tanpa dukungan dari elemen lain. Elemen-elemen yang ada dalam marketing mix

\footnotetext{
${ }^{2}$ Philip Kotler, Prinsip-prinsip Pemasaran Edisi I2, Jakarta: Erlangga,2008, hal 62
} 
adalah produk (product), Harga (Price), Lokasi ( Place) dan promosi (promotion). ${ }^{3}$

a. Produk (product). Produk secara umum di artikan sebagai sesuatu yang dapat memenuhi kebutuhan dan keinginan pelanggan. Artinya apapun wujudnya, selama itu dapat memenuhi keinginan pelanggan dan kebutuhan kita katakana sebagai produk. Philip kotler mendefinisikan produk sebagai sesuatu yang dapat ditawarkan ke pasar untuk mendapatkan perhatian untuk dibeli, untuk digunakan atau dikonsumsi yang dapat memenuhi keinginan dan kebutuhan. Untuk dunia perbankan, nasabah tidak akan datang dengan sendirinya tanpa ada sesuatu yang menarik perhatian, sehingga berminat untuk membeli produk bank. Untuk menarik minat nasabah, bank harus memilki produk unggulan yang tidak dimiliki bank bank lain. Bank harus memiliki strategi untuk mengembangkan produk diantaranya sebagai berikut :

I. Penentuan logo dan motto Logo merupakan ciri khas suatu bank, sedangkan motto merupakan serangkaina kata-kata yang berisikan visi dan misis bank dalam melayani masyarakat. Baik logo maupun motto harus dirancang dengan benar, seperti harus memiliki arti, menarik perhatian, mudah diingat dan menciptakan merk.

2. Menciptakan merk Untuk smua produk-produk yang dikeluarkan bank harus memiliki merk tertentu. Merek digunakan sebagai sesuatu untuk mengenal barang atau jasa yang ditawarkan. Yang harus diperhatikan dalam menciptakan suatu merk adalah mudah di ingat, terkesan hebat dan modern, memiliki arti, menarik perhatian. Bagi penjual merk dapat menambah ukuran prestice untuk dibedakan dari komoditas biasa lainnya. ${ }^{4}$

3. Menciptakan kemasan kemasan merupakan pembungkus suatu produk. Dala dunia perbankan kemasan lebih diartikan kepada pemberian

${ }^{3}$ mukhlas, abd arif. (2020). Manajemen Bisnis Rasulullah. AL IQTISHOD: Jurnal Pemikiran Dan Penelitian Ekonomi Islam, 8(1), 46-52. Retrieved from https://jurnal.staialazharmenganti.ac.id/index.php/Allqtishod/article/view/87

${ }^{4}$ William J. Stanto, Prinsip Pemasaran, Jakarta: Erlangga, I984, hal 270

Volume. 9/No. I/Januari 202I A1-Iqtishod|95 
Implementasi Marketing Mix ....

pelayanan atau jasa kepada para nasabah disamping juga sebagai pembungkus untuk beberapa jenis jasanya seperti buku tabungan, cek, bilyet giro atau kartu kredit.

4. Keputusan label Label merupakan sesuatu yang dilengketkan pada produk yang ditawarkan dan merupakan bagian dari kemasan. Di dalam label menjelaskan siapa yang membuat, dimana di buat, cara menggunakannya dan informasi lainnya,

b. Harga Penentuan harga menjadi sangat penting untuk diperhatikan, mengingat harga sangat menentukan laku tidaknya produk dan jasa perbankan. Salah dalam menentukan harga akan berkibat fatal terhadap produk yang ditawarkan. Penentuan harga oleh suatu bank dimaksudkan untuk berbagai tujuan yang hendak dicapai diantaranya sebagai berikut :

I. Untuk bertahan hidup Bank menentukan harga semurah mungkin agar produk atau jasa bank dapat laku dipasaran.

2. Untuk memaksimalkan laba. Tujuan harga dimaksudkan untuk meningkatkan tingkat keuntungan.

3. Untuk memperbesar market share. Tujuan harga ini adalah untuk meningkatkan jumlah pelanggan sekaligus diharapkan para nasabah akan beralih dari produk bank lain ke produk bank kita.

4. Mutu produk. Tujuan ini adalah untuk memberikan kesan bahwa produk atau jasa yang ditawarkan memiliki kwalitas yang tinggi dan harga jualnya pun tinggi.

5. Karena pesaing. Dalam hal ini bertujuan agar harga yang kita tetapkan tidak melebihi atau kurang dari harga pesaing.

c. Lokasi (place). Penentuan lokasi bagi industry perbankan lebih ditekankan kepada lokasi cabang. Lokasi yang tidak strategis akan mengurangi minat nasabah untuk berhubungan dengan bank. Secara umum pertimbangan dalam menentukan letak suatu bank seabagai berikut :

96| A1-Iqtishod Volume. 9/No. I/Januari 202I 
I. Dekat dengan kawasan industry atau pabrik

2. Dekat dengan lokasi perkantoran

3. Dekat dengan lokasi pasar

4. Dekat dengan lokasi perumahan atau masyarakat

5. Mempertimbangakan jumlah pesaing yang ada disekitar lokasi

Setelah penentuan lokasi langka selanjutnya adalah menentukan layout gedung dan ruang kantor. Hal-hal yang perlu diperhatikan dalam penentuan layout adalah :

a. Bentuk gedung yang memberikan kesan bonafit atau modern atau mungkin tradisional tergantung diwilayah mana yang akan di buka.

b. Lokasi parker luas dan aman

c. Keamanan disekitar gedung

d. Tersedia tempat ibadah

e. Tersedia telpon umum atau fasilitas lainnya khusus untuk nasabah

Hal-hal yang perlu dipertimbangkan dalam penentuan layout gedung dan ruangan sebagai berikut :

I. Bentuk gedung

2. Suasana ruangan terkesan luas dan lega

3. Ruangan yang sejuk dan nyaman

4. Tata letak meja dan kursi yang apik dan rapi

5. Hiasan dalam ruangan yang membuat ruangan menjadi hidup

6. Sarana hiburan seperti music sebagai alat untuk mngusir kebosanan

Factor-faktor yang menjadi pertimbangan dalam penyusunan peralatan ruangan suatu lembaga keuangan sebagai berikut :

I. Produk yang dihasilkan

2. Banyaknya ruangan yang dibutuhkan

3. Urutan operasi (dari customer service, teller, bagian administrasi dan seterusnya)

Volume. 9/No. I/Januari 202I A1-Iqtishod|97 
Implementasi Marketing Mix ....

4. Aliran orang dan dokumen

5. Pendingin ruangan dan sirkulasi udara

6. Dekirasi ruangan

7. Fleksibelitas (kemudahan berpindah-pindah)

d. Promosi (promotion). Promosi adalah cara langsung atau tidaka langsung untuk mempengaruhi konsumen agar lebih suka membeli suatu merk barang tertentu. $^{5}$

Dalam kegiatan ini setiap bank berusaha untuk mempromosikan seluruh produk dan jasa yang dimilikinya baik langsung maupun tidak langsung. Salah satu tujuan promosi adalah menginformasikan segala jenis produk yang ditawarkan dan berusaha menarik calon nasabah yang baru. Ada empat macam sarana promosi yang dapat digunakan dalam mempromosikan baik produk maupun jasanya yaitu:

a. Periklanan (advertising). Penggunaan promosi dengan iklan dapat dilakukan dengan berbagai media seperti :

I. Pemasangan Billboard dijalan strategis

2. Pencetakan brosur baik disebarkan disetiap cabang atau pusat-pusat perbelanjaan

3. Pemasangan spanduk di lokasi tertentu yang strategis

4. Pemasangan melalui Koran

5. Pamasangan melalui majalah

6. Pemasangan melalui televise

7. Pemasangan melalui radio

b. Promosi penjualan (sales promotion). Promosi penjualan adalah suatu penunjang kekuatan promosi yang membantu dan melengkapi usaha utama dari bagian penjualan atau iklan. Bagi lembaga keuangan promosi penjualan dapat dilakukan melalui :

${ }^{5}$ O.P.Simorangkir, Pengantar Pemasaran Bank, Jakarta:I988, Hal II I

98| A1-Iqtishod Volume. 9/No. I/Januari 202I 
I. Pemberian bagi hasil

2. Pemberian intensif

3. Pemberian cinderamata

c. Penjualan pribadi. Adalah interaksi individu, antara lain pertemuan tatap muka dengan maksud untuk menciptakan, memperbaiki, mengawasi, atau mempertahankan hubungan yang saling menguntungkan satu sama lain.

d. Humas Humas menduduki tempat yang unik dalam sejarah perbankan. Seorang karyawan humas bekerja sepenuhnya yang berorientasi pada nasabah. Humas juga berfungsi sebagai manajemen yang memberikan penilaian tentang sikap masyarakat, identitas suatu kebijaksanaan secara individu atau organisasi. ${ }^{6}$

\section{Metode Penelitian}

Untuk mengkaji penelitian ini maka digunakan metode kualitatif dengan melakukan pendekatan metode studil iteratur (library research).Penelitian ini dilakukan dengan membaca serta melakukan berbagai hal terutama mempelajari berbagai literature- literatur yang ada, yang didapatmelaluimetode documenter, yang bersumberdaribuku, jurnal, internet, danmakalah. ${ }^{7}$

Setelah semua data terkumpul kemudian data akan dianalisis dengan beberapa cara, diantaranya yaitu: Pertama, Interprestasi, adalah upaya tercapainya pemahaman yang benar terhadap fakta, data dan gejala. Kedua, koheresi intern, yaitu agar pemikiran tokoh dapat dipahami secara tepat, maka seluruh konsep pemikirannya dilihat menurut keselarasannya antara satu dengan yang lain. Ketiga, holistika adalah pandangan menyeluruh atau totalitasi; semua dipandang dalam kesinambungannya dengan satu totalitas. Keempat, heuristika yaitu berdasarkan bahan-bahan baru, metodologi baru, maka peneliti berusaha untuk menemukan pemahaman baru.

${ }^{6}$ O.P.Simorangkir, Pengantar Pemasaran Bank, Jakarta:1988, Hal I23

7'Sugiyono, MetodePenelitianBisnis, (Alfabeta: Bandung, 20I4), hal. 399

Volume. 9/No. I/Januari 202I A1-Iqtishod|99 
Implementasi Marketing Mix ....

Setelah semua data terkumpul dan telah dilakukan analisa, maka dapat dijelaskan secara umum bagaimana hendaknya penelitian ini disusun secara disiplin agar isinya dapat dipahami secara runtut dan analistis.

\section{Hasil dan Pembahasan}

\section{Pengertian pemasaran}

Dalam pandangan para ahli, pemasaran memiliki berbagai macam makna dan definisi tersendiri. Hal ini seperti diungkapkan Philip Kotler mendefinisikan pemasaran sebagai "Suatu proses social dan manajerial yang mana individu dan kelompok memperoleh apa yang mereka butuhkan dan inginkan dengan cara menciptakan serta mempertukarkan produk dan nilai dengan pihak lain"."

Sementara Menurut William J. Stanton pemasaran adalah” suatu system keseluruhan dari kegiatan bisnis yang ditujukan untuk merencanakan, menentukan harga, mempromosikan dan mendistribusikan barang dan jasa yang memuaskan kebutuhan baik kepada nasabah yang ada maupun nasabah potensia. ".?

Secara umum pengertian pemasaran bank adalah suatu proses untuk menciptakan dan mempertukarkan produk atau jasa bank yang ditujukan untuk memenuhi kebutuhan dan keinginan nasabah dengan cara memberikan kepuasan.

Berdasarkan pandangan para ahli diatas dapat dipahami bahwa manajemen pemasaran adalah proses perencanaan dan pelaksanaan dari perwujudan, pemberian harga, promosi dan distribusi dari barang-barang, jasa dan gagasan untuk menciptakan pertukaran dengan kelompok sasaran yang memenuhi tujuan pelanggan dan organisasi. ${ }^{10}$

\footnotetext{
${ }^{8}$ Philip Kotler, Prinsip-prinsip Pemasaran Edisi I2, Jakarta: Erlangga,2008, hal 6

${ }^{9}$ William J. Stanto, Prinsip Pemasaran, Jakarta: Erlangga, 1984, hal 7

${ }^{10}$ Sentot Imam Wahjono, Manajemen Pemasaran Bank, Yogyakarta: Graha Ilmu, 20I0, Hal 2
} 


\section{Implementasi marketing mix dalam pemasaran perbankan syariah}

Merencanakan strategi yang baik hanyalah permulaan menuju pemasaran yang berhasil. Strategi pemasaran yang brilian tidak akan berarti jika perusahaan gagal mengimplementasikannya dengan tepat. Implementasi pemasaran (Marketing Implementation) adalah proses yang mengubah rencana pemasaran menjadi tindakan pemasaran untuk mencapai tujuan pemasaran strategis. ${ }^{11}$

Banyak manajer berfikir bahwa "melakukan hal yang benar" (implementasi) sama pentingnya, atau bahkan lebih penting daripada melakukan hal yang benar" (strategi). Faktanya kedua hal tersebut penting bagi kesuksesan, dan perusahaan bisa memperoleh keunggulan kompetitif melalui implementasi yang efektif. Salah satunya yang bersasal dari strategi pemasaran yang dilakukan oleh bank syariah melalui strategi bauran pemasaran (marketing mix). Yang di dalamnya meliputi kebijakan produk, harga, promosi, tempat dan saluran distribusi, pelayanan pegawai, proses pelayanan, dan bentuk fisik kantor Bank Syariah itu sendiri. Sehingga dari bauran pemasaran terebut nasabah dapat terpengaruh untuk mau berhubungan dengan Bank Syariah. Bauran pemasaran di nilai dapat mempengaruhi pertimbangan konsumen untuk mau menjadi nasabah bank syariah. ${ }^{12}$

Nilai produk dapat di evaluasi oleh nasabah melalui manfaat yang dapat ditawarkan oleh produk tersebut dibandingkan dari produk lain. Selain itu nasabah akan tertarik menjadi nasabah bank syariah karena produk yang ditawarka cukup inovatif yaitu produk yang memiliki kegunaan yang urang leih sama dengan bank

\footnotetext{
${ }^{11}$ Philip Kotler, Prinsip-prinsip Pemasaran Edisi I2, Jakarta: Erlangga,2008, hal 65

${ }^{12}$ sutono, sutono. (2020). IMPLIKASI AKAD MUSYARAKAH MUTANAQISAH PERBANKAN SYARI'AH. AL IQTISHOD: Jurnal Pemikiran Dan Penelitian Ekonomi Islam, $\quad 8(2), \quad$ I-I9. Retrieved from https://jurnal.staialazharmenganti.ac.id/index.php/Allqtishod/article/view/I52
} 
Implementasi Marketing Mix ....

konvensional pada umumnya tetapi dikemas dalam bentuk yang berbeda, yang di sesuaikan dengan prinsip-prinsip islam. ${ }^{13}$

Nilai harga dapat di evaluasi nasabah melalui biaya administrasi, setoran minimum, dan prosentase bagi hasil yang ditawarkan bank syariah. Nilai lokasi bagi nasabah sangat penting, karena nasabah akan memutuskan menjadi nasabah suatu bank syariah yang berada pada lokasi yang cukup strategis dan mudah dijangkau alat transportasi.

Nilai pelayanan, bagi nasabah hal yang tidak kalah penting adalah masalah pelayanan, nasabah akan cenderung merasa nyaman berada di bank syariah. Seperti membudayakn senyum, salam, sapa pada saat ada nasabah akan memasuki bank. ${ }^{14}$

Nilai personil/ karyawan merupakan asset tersembunyi yang pemanfaatannya harus dimaksimalkan oleh bank. Karyawan bank yang menguasai produk/jasa yang ditawarkan dan yang responsive terhadap keinginan nasabah dan mendorong nasabah melakukan transaksi dan bahkan loyal terhadap bank atau menbuat nasabah tidak berpaling ke bank lain.

\section{E. Simpulan}

Penerapan marketing mix dalam pemasaran perbankan syariah sangat penting keberadaannya. Dengan adanya bauran pemasaran ini bagi nasabah dapat dijadikan diantaranya adalah nilaipedoman dalam memilih bank mana yang sesuai dengan aturan yang berlaku. Sedangkan bagi bank sendiri dapat dijadikan acuan dalam menarik nasabah

\footnotetext{
${ }^{13}$ kholishudin, kholishudin. (2020). PENGAMBILAN KEPUTUSAN INVESTASI GENERASI Y TERHADAP PRODUK TABUNGAN EMAS DI PEGADAIAN SYARIAH CABANG BABAKAN, KOTA SURABAYA. AL IQTISHOD: Jurnal Pemikiran Dan Penelitian Ekonomi Islam, $\quad 8(2), \quad 91-105 . \quad$ Retrieved from alazharmenganti.ac.id/index.php/Allqtishod/article/view/156

14 kambali, muhammad. (2020). Pemikiran Karl Marx Tentang Struktur Masyarakat. $A L$ IQTISHOD: Jurnal Pemikiran Dan Penelitian Ekonomi Islam, 8(2), 63-80. Retrieved from https://jurnal.stai-alazharmenganti.ac.id/index.php/Allqtishod/article/view/154
}

I02| A1-Iqtishod Volume. 9/No. I/Januari 202I 
sebanyak-banyaknya. Strategi bauran pemasaran yang dipakai bank syariah nilai produk, nilai harga, nilai lokasi, nilai pelayanan, dan nilai karyawan.

\section{F. Daftar Pustaka}

Philip Kotler, Prinsip-prinsip Pemasaran Edisi I2, Jakarta: Erlangga,2008, hal 62 mukhlas, abd arif. (2020). Manajemen Bisnis Rasulullah. AL IQTISHOD: Jurnal Pemikitan Dan Penelitian Ekonomi Islam, 8(I), 46-52. Retrieved from https://jurnal.staialazharmenganti.ac.id/index.php/AlIqtishod/article/view/87

William J. Stanto, Prinsip Pemasaran, Jakarta: Erlangga, 1984

O.P.Simorangkir, Pengantar Pemasaran Bank, Jakarta:I988

Sugiyono, MetodePenelitianBisnis, Alfabeta: Bandung, 2014

Sentot Imam Wahjono, Manajemen Pemasaran Bank,Yogyakarta: Graha Ilmu, 2010

Philip Kotler, Prinsip-prinsip Pemasaran Edisi I2, Jakarta: Erlangga,2008

sutono, sutono. (2020). IMPLIKASI AKAD MUSYARAKAH MUTANAQISAH PERBANKAN SYARI'AH. AL IQTISHOD: Jurnal Pemikiran Dan Penelitian Ekonomi Islam, 8(2), I-I9. Retrieved from https://jurnal.staialazharmenganti.ac.id/index.php/AlIqtishod/article/view/I52

kholishudin, kholishudin. (2020). PENGAMBILAN KEPUTUSAN INVESTASI GENERASI Y TERHADAP PRODUK TABUNGAN EMAS DI PEGADAIAN SYARIAH CABANG BABAKAN, KOTA SURABAYA. $A L$ IQTISHOD: Jurnal Pemikiran Dan Penelitian Ekonomi Islam, 8(2), 9I-I05. Retrieved from alazharmenganti.ac.id/index.php/AlIqtishod/article/view/I56

https://jurnal.stai-

kambali, muhammad. (2020). Pemikiran Karl Marx Tentang Struktur Masyarakat. AL IQTISHOD: Jurnal Pemikiran Dan Penelitian Ekonomi Islam, 8(2), 6380. Retrieved from https://jurnal.staialazharmenganti.ac.id/index.php/AlIqtishod/article/view/I54

Kambali, M. (2020). Analisa Faktor-Faktor Yang Mempengaruhi Keputusan Nasabah Untuk Menggunakan Jasa Bank Syariah Mandiri (Studi Kasus Pada Nasabah Bank Syari’ah Mandiri Gresik). AL IQTISHOD: Jurnal Pemikiran Dan Penelitian Ekonomi Islam, 8(I), 53-6I. Retrieved from https://jurnal.stai-

alazharmenganti.ac.id/index.php/AlIqtishod/article/view/88

Volume. 9/No. I/Januari 202I A1-Iqtishod | 103 